DIVISION OF THE HUMANITIES AND SOCIAL SCIENCES

CALIFORNIA INSTITUTE OF TECHNOLOGY

PASADENA, CALIFORNIA 91125

CAN WE INSURE AGAINST POLITICAL UNCERTAINTY? EIVDENCE FROM THE U.S. STOCK MARKET

Andrea Mattozzi

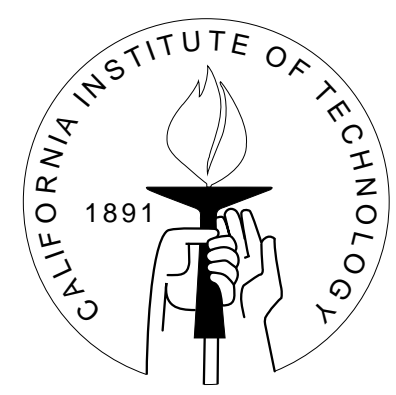

SOCIAL SCIENCE WORKING PAPER 1207 


\title{
Can We Insure Against Political Uncertainty? Evidence from the U.S. Stock Market
}

\author{
Andrea Mattozzi
}

\begin{abstract}
We show that existing stocks that are currently traded in the U.S. stock market can be used to hedge political uncertainty. Focusing on the 2000 U.S. Presidential election, we construct two "presidential portfolios" composed of selected stocks anticipated to fare differently under a Bush versus a Gore presidency. To construct these portfolios we use data on campaign contributions by publicly traded corporations and identify the major contributors on each side. Using daily observations for the six months before the election took place, we show that the excess returns of these portfolios with respect to overall market movements are significantly related to changes in electoral polls.
\end{abstract}

JEL classification numbers: D7, G10.

Key words: Political Uncertainty, Financial Markets 


\title{
Can We Insure Against Political Uncertainty? Evidence from the U.S. Stock Market*
}

\author{
Andrea Mattozzi
}

\section{Introduction}

Political uncertainty is a pervasive phenomenon which is inherent to the political process. It naturally arises because different candidates running for office if elected will implement different policies, and election results are uncertain; that is what happened, for example, in the 2000 Presidential election in the United States. This leads to the following important questions: Is political uncertainty insurable? More important, do existing financial instruments allow individuals to hedge political uncertainty?

We show that existing stocks that are currently traded on the U.S. stock market can be used to insure against political uncertainty. Focusing on the 2000 U.S. Presidential election, we construct two "presidential portfolios" composed of selected stocks anticipated to fare differently under a Bush versus a Gore presidency. To construct these portfolios we use data on campaign contributions by publicly traded corporations and identify the major contributors on each side (excluding corporations that made significant contributions to both candidates' campaigns). Using daily observations for the six months before the election took place, we show that the excess returns of these portfolios with respect to overall market movements are significantly related to changes in electoral

*I am grateful to Bob Inman, Andrew Postlewaite, Frank Schorfheide, and in particular to Antonio Merlo for their comments and encouragement. I also benefitted from discussions with Celso Brunetti, Marco Cozzi, Jan Eeckhout, Daniela Iorio, Dirk Krueger and Nicola Persico. All usual disclaimers apply. 
polls. In particular, an increase in the probability of a Bush victory from 50 to 51 percent, increases the annual expected excess return of the Bush portfolio by 25 percent and decrease the annual expected excess return of the Gore portfolio by 35 percent.

Based on this evidence, we conclude that the presidential portfolios we have constructed can actually be used as an instrument to hedge political uncertainty. Moreover, given our selection strategy, individuals can easily identify politically sensitive stocks well before an election, using readily available information.

The remainder of the paper is organized as follows. Section 2 reviews the literature. Section 3 describes the data used in the empirical analysis. Results and sensitivity analysis are presented in Section 4. Section 5 offers concluding remarks and some avenues for future research.

\section{Related Literature}

Roberts [1990] is among the first papers that analyzes the effects of political events on stock market performance and, in particular, whether expected changes in government policy are manifested in the value of "policy sensitive" securities. He finds a positive relation between stock returns in the defense industry and the probability of a Reagan victory in the 1980 U.S. Presidential election.

Knight [2003] tests whether policy platforms are capitalized into equity prices, using data from the 2000 U.S. Presidential election. He selects a sample of firms favored under the alternative policy platforms, and shows that campaign platforms matter for firms' profitability. Firms are selected using report from financial analysts, and the selected firms' campaign contributions are used ex-post to support his baseline estimates. In a similar vein, Herron et al. [1999] study the effect of the 1992 U.S. Presidential election outcome on the profitability of different economic sectors, and Ayers et al. [2003] study whether security prices reflect fiscal policy uncertainty, using data from the same election.

At a more aggregate level, Pantzalis et al. [2000] investigate the behavior of stock market indices for a cross section of countries in the period around national elections. 
They find evidence of a positive abnormal return during the two weeks before election are held. Santa-Clara and Valkanov [2003] analyze the excess market return in eighteen Presidential terms between 1927 and 1998. They find evidence that the excess return is at least 9 percent higher under Democratic than Republican presidencies. They also show that this difference seems not to be related to business-cycle variables nor to proximity to elections.

None of the above papers address the issue whether political uncertainty can be insured. Furthermore, the use of data on campaign contribution to identify stocks anticipated to fare differently under different electoral outcomes is novel in the literature.

Recent theoretical works in political economy have focused on the implication that an insurance against political uncertainty can have on popular support for government policies (see Musto and Yilmaz [2003] and Mattozzi [2004]). In particular, the existence of a "political insurance market" may affect the equilibrium demand for redistributive policies, and, in turn, the likelihood that such policies will ultimately be implemented. Mattozzi [2004] proposes an equilibrium model where agents, heterogeneous with respect to their income, can trade policy-contingent securities and then vote on a redistribution policy whose probability of adoption increases with the number of its supporters. He shows that as long as some individuals do not have access to the policy insurance market, the demand for redistribution is always smaller than in the case where no insurance is available. In equilibrium, relatively poor individuals receive private transfers from the rich through the insurance market, and oppose a public redistribution policy that they would otherwise have supported. The evidence presented in this paper suggests that insurance markets of this type may exist.

\section{Data}

The 2000 U.S. Presidential election provides a natural opportunity to study whether the stock market provides insurance against policy uncertainty for several reasons. First, it was a very close election with no incumbent. Uncertainty about the identity of the winner lasted until December 12th, when the Supreme Court made a final decision about the 
Florida recount, and George W. Bush's final victory was determined by a handful of votes. Second, the expected policies of the two candidates differed clearly on crucial issues like fiscal policy, social security reform and defense and drug administration policies. Finally, for the first time the press devoted considerable attention to the issue of election-related investing strategies. ${ }^{1}$

We construct presidential portfolios composed of selected stocks anticipated to fare differently under the alternative candidates and investigate to what extent the price movements of these portfolios are correlated with electoral polls in the period prior to the elections. If the probability of one candidate victory is significantly correlated with price movements of stocks and individuals can identify these stocks well before the election, then they can construct portfolios that approximate an "electoral" elementary security, and hedge policy risk by trading these securities.

The strategy we follow to construct these portfolios uses data about campaign contributions and selects stocks of corporations satisfying three conditions: i) they made significant contributions to candidates' campaigns in the 2000 election cycle, ii) the contributions were concentrated on one candidate, iii) corporation's stocks were publicly traded in the New York Stock Exchange (NYSE) during the year 2000. Table I lists the top ten donors, among publicly traded corporations, that gave more than two thirds of their total contributions to the republican party in the 2000 election cycle. Since the top overall donors for the democratic party were typically trade unions and professional associations, in order to include publicly traded corporations that made significant donations (above one million dollars) in the "Gore portfolio", we considered a slightly lower threshold, and included those corporations that gave more than 60 percent of their total contributions to the democratic party. Table II lists the top ten donors for the democratic party. Data are taken from the Center of Responsive Politics and Common Cause.

Using overall campaign contributions (hard and soft money) as a selection criterion

\footnotetext{
1 "Presidential race spurs the creation of index strategies." Wall Street Journal [2000]

"It appears that one can assign potential industry winners and losers to each candidate, known therefore as Bush Stocks and Gore Stocks."... "Wall Street consultancy ISI Group and investment firms Lehman Brothers and Prudential Securities have each come up with portfolios of so-called Bush stocks and Gore stocks." Business Week [2000]
} 
has two important features: it exploits the corporation expectations about the future states, and it makes the selection possible from an ex-ante point of view, using information readily available to the general public. ${ }^{2}$ On the other hand, including soft money contributions has a well-known problem: it is difficult to distinguish between funds used to finance the presidential campaign from funds used for other party expenditures. However, since our main interest is in selecting corporations with a strong preference for one policy platform with respect to the other, we believe that the choice of considering total party contributions is plausible. ${ }^{3}$ It is worth noting that the stocks selected are a subset of the so called "Bush Stocks" and "Gore Stocks" that Prudential Securities and Lehman Brothers, among others, picked during the 2000 U.S. Presidential election campaign. They are also part of the call and put options on Bush and Gore baskets issued by the Swiss firm Vontobel the day after the elections.

As a measure for the probability of each candidate being elected we use daily data from the Iowa Political Stock Market (henceforth IPSM). The IPSM is an experimental market operated by the University of Iowa. In the "winner-take-all market" internet traders can buy or sell candidate shares that pay $\$ 1$ if the candidate wins and zero otherwise. In equilibrium, a $\$ 0.51$ price of a Bush contract represents a probability of 51 percent of a Bush victory. The IPSM is used in several empirical studies as a poll proxy, and has been shown to be particularly accurate in predicting election outcomes. ${ }^{4}$ We use the daily closing price of the Bush contract, normalized to eliminate the effect of third candidates running. It should be noticed here that the IPSM is not a policy insurance market per-se since there is a $\$ 500$ upper limit on how much people can invest in the market. Figure I plots the IPSM closing price of a Bush contract from the first day the "winner-take-all market" was open for trading (5/1/2000) to the 2000 U.S. Presidential election day $(11 / 6 / 2000)$.

We construct two weighted portfolios composed of the stocks listed in Table I and

\footnotetext{
${ }^{2}$ The ranking of of top overall campaign contributors to each candidate did not change in the last months before the election. Typically, big donors start contributing early in the campaign.

${ }^{3} \mathrm{~A}$ possible alternative is to distinguish between soft money contributions to Party National Committees and other contributions. This strategy addresses the problem only partially and requires an additional amount of information not readily available to the general public.

${ }^{4}$ See Forsythe et al. [1992].
} 
Table II. ${ }^{5}$ Each index is an average of the daily closing price of ten stocks traded in the NYSE. Weights are constructed using the value of outstanding shares. In particular, let $p_{i j t}$ and $v_{i j t}$ be respectively day $t$ closing price and number of outstanding shares of stock $j$ in portfolio $i=\{$ Bush, Gore $\}$, then the portfolio index $I_{i t}$ can be computed as:

$$
I_{i t}=\sum_{j=1}^{10} p_{i j t} w_{i j t},
$$

where

$$
w_{i j t}=\frac{p_{i j t} v_{i j t}}{\sum_{j=1}^{10} p_{i j t} v_{i j t}}
$$

The total capitalization of all corporations included in the Bush portfolio is more than 600 billion dollars, approximately 3.5 percent of the capitalization of all companies listed in the NYSE. The companies included in the Gore portfolio are on average much smaller and the total capitalization is about 300 billion dollars. Figure II plots the series of the two presidential indexes for the period 5/1/2000 to $11 / 6 / 2000$. Both series are normalized to unity in date $5 / 1 / 2000$.

Simple inspection of Figures I and II reveals that the two presidential portfolios are negatively correlated, in particular from September 2000 to the election day, and there is evidence of a positive correlation between the price of the Bush portfolio and the price of the Bush contract traded in the IPSM. The annualized average rates of return of the Bush and Gore indexes in the sample period were, respectively, 9.5 percent and -8.6 percent. In the same period the Standard and Poor's 500 index fell by 2.5 percent. On August 18th, one day after Al Gore's speech at the Democratic National Convention in which he accused the major pharmaceutical firms of overcharging the public, the Bush index fell by 1.6 percent, and Pfizer alone fell by 2.9 percent. On December 12 th, when all uncertainty was finally resolved, the Bush index rose by 0.8 percent with an increase in volumes traded of 12 percent, while the Gore index fell by 0.7 percent.

\footnotetext{
${ }^{5}$ Credit Suisse First Boston was excluded form the Bush portfolio because of several missing price observations in the six months period considered in the empirical analysis, and replaced with UST Inc. $(\$ 1,605,652$ to the republicans that accounts for 90 percent of its total contributions). Nonetheless, our result are qualitatively the same if we interpolate missing observations and include Credit Suisse First Boston in the Bush portfolio.
} 


\section{Results}

To test whether the daily returns of the presidential portfolios are correlated with changes in the expected probability of a Bush victory we estimate a Capital Asset Pricing Model (CAPM) of the form:

$$
R_{i t}-R_{F t}=\beta_{1}\left(R_{M t}-R_{F t}\right)+\beta_{2} R_{I P S M t-1}+\varepsilon_{i t},
$$

where all variables are annualized rates of return, and:

$$
\begin{aligned}
R_{i t} & =\text { return of presidential portfolio } i=\ln \left(\frac{I_{i t}}{I_{i t-1}}\right) * 252 \\
i & =\{\text { Bush, Gore }\} \\
R_{M t} & =\text { return of value weighted NYSE index } \\
R_{F t} & =\text { return of risk free asset } \\
R_{I P S M t} & =\text { return of a Bush contract in the winner-takes-all market (IPSM). }
\end{aligned}
$$

As a measure for the risk free rate of return we used the 3 months treasury bill traded on the secondary market. In order to control for factors that affected overall returns, we included the rate of return of a value weighted index of all stocks traded on the NYSE. Moreover, since, unlike NYSE, the IPSM is open for trading 24 hours a day and we used the midnight price as closing price, we considered one period lagged daily changes of the Bush contract closing price.

Table III reports the results of a OLS regressions of the CAPM in terms of excess returns for both portfolios. The estimate of $\beta_{2}$, the coefficient that capture the effect of changes in the probability of a Bush victory on excess return of presidential portfolios, is significant in both regression, has the expected sign, and the estimates do not change if we consider a different specification where the independent variable is the simple return and we include a constant term as in Table IV.

In order to interpret the magnitude of the estimated coefficients, let us consider the example of an increase in the probability of a Bush victory from 0.5 to 0.51 . If this is the case, the annual expected excess return of the Bush portfolio increases by approximately $\ln \left(\frac{0.51}{0.5}\right) \times 0.05 \times 252 \times 100 \stackrel{\sim}{=} 25$ percent. The opposite happens if we consider the Gore portfolio. The annual expected excess return of the Gore portfolio 
decreases by $\ln \left(\frac{0.51}{0.5}\right) \times 0.07 \times 252 \times 100 \cong 35$ percent. Therefore, even if our portfolios are not elementary securities, they have significantly different values in different states of the world, and can actually be used as an instrument to hedge political uncertainty.

Consider, for example, that based on the proposed income tax policies of the two presidential candidates, Deloitte and Touche calculated that a married couple earning $\$ 80,000$ with two children, one under 17 , was expected to get approximately $\$ 1500$ less in case of a Gore victory with respect to a Bush victory. By investing less than $\$ 30,000$ in the Gore portfolio, they would have been able to completely hedge the income tax policy uncertainty. Moreover, consider that in 2001, the proportion of U.S. households owning stocks directly or indirectly (through mutual funds or retirement accounts) was almost 52 percent, and the median value of stock holdings for families holding asset and income in the 80-89.9 percentiles was approximately $\$ 20,000{ }^{6}$

\subsection{Sensitivity Analysis}

The Lagrange multiplier tests reported in Table III and IV suggest that we cannot reject the hypothesis of first order autoregressive conditional heteroskedasticity in the residuals of the Gore portfolio regressions. In order to deal with this problem, we estimate a GARCH $(1,1)$ model under the assumption of conditionally normally distributed errors. As Table $\mathrm{V}$ shows the point estimate of $\beta_{2}$ does not change, and it is still significant at the 5 percent level. More important, as one should expect if the variance equation is correctly specified, there is no more autoregressive conditional heteroskedasticity left in the standardized residuals of the Gore portfolio equation.

Figure III and IV show respectively a scatter plot of the residuals of a regression of $R_{I P S M t-1}$ on a constant $c_{1}$ and $R_{M t}$, and the residuals of a regression of $R_{i t}$ on a constant $c_{2}$ and $R_{M t}$.

$$
\begin{aligned}
& \text { Iowa Residuals }=R_{I P S M t-1}-\left(\hat{c}_{1}+\hat{\gamma}_{1 O L S} R_{M t}\right) \\
& i \text { Portfolio Residuals }=R_{i t}-\left(\hat{c}_{2}+\hat{\gamma}_{2 O L S} R_{M t}\right) .
\end{aligned}
$$

\footnotetext{
${ }^{6}$ See Bertaut and Starr-McCluer [2002], and Aizcorbe, Kennickell and Moore [2003].
} 
As it is apparent form Figure III and IV, there are few outlier observations that might affect the correlation result. Therefore, as a way to reduce the weight of these observations given the small sample, we estimate the model by a median regression (least absolute value). The results reported in Table VI provide evidence that the estimated effect of changes in the return of a IPSM Bush contract are robust to the presence of outliers. In particular, changes in the probability of a Bush victory have a positive effect on Bush portfolio returns, and are still significant at the 5 percent level. For the Gore portfolio we get the expected sign, and the estimate is significant at the 10 percent level.

\section{Conclusion}

We provide empirical evidence that securities currently traded in the U.S. Stock market can be used to insure against political uncertainty. Individuals can identify stocks whose returns are significantly correlated with the probability of one presidential candidate victory. Moreover, they can do it well before the election, without resorting to particularly sophisticated financial instruments, and the selection strategy suggested is a particularly intuitive and simple one.

The natural next step in this research agenda is to explore whether people systematically hedge policy risk. Measuring the extent to which people insure against political uncertainty is very difficult. The lack of data on stock holdings at the individual level makes it very hard to explore this issue from an empirical point of view. However, given that in the U.S. the majority of stock owners participate in the market through their mutual fund holdings, a promising avenue for addressing this question is to explore the CDA Spectrum database. This database provides information on each stock owned by mutual funds for each calendar quarter. ${ }^{7}$ For example, it is possible to see that before the 2000 U.S. Presidential election the Vanguard Health Care fund, a five star rating fund from Morningstar.com, decreased by more than six million dollars its stock holdings of Pfizer but then after the election bought back almost two million dollars of stocks. It is inter-

\footnotetext{
${ }^{7}$ One problem with using the Spectrum database is the so called "window-dressing" practice. Since the information available is only a snapshot every quarter, funds managers might choose to readjust their portfolio holdings just before data are released.
} 
esting to note that Pfizer was a "Bush stock", and the performance of pharmaceuticalsoriented funds would presumably have been harmed by a Gore presidency. We plan to explore this issue further in future research. 


\section{References}

[1] Aizcorbe, A.M., A.B. Kennickell, and K.B. Moore, "Recent Changes in U.S. Family Finances: Evidence from the 1998 and 2001 Survey of Consumer Finances," Federal Reserve Bulletin, I (2003).

[2] Ayers, B., C.B. Cloyd, and J.R. Robinson, "Read My Lips . . . Does the Tax Rhetoric of Presidential Candidates Affect Security Prices?," The Journal of Law and Economics, forthcoming.

[3] Bertaut, C.C. and M. Starr-McCluer, "Household Portfolios in the United States," in L. Guiso et al., eds., Household Portfolios, (MIT Press, 2002).

[4] Erikson, M., A. Goolsbee, and E. Maydew, "How Prevalent is Tax Arbitrage? Evidence from the Market for Municipal Bonds," National Tax Journal, LVI (2003), 259-270.

[5] Forsythe, R., F. Nelson, and J. Wright, "Anatomy of an Experimental Political Stock Market," American Economic Review, LXXXII (1992), 1142-1161.

[6] Guiso, L., M. Haliassos, and T. Jappelli, Household Portfolios, (MIT Press, 2002).

[7] Herron, M.C., J. Lavin, J. Silver, and D. Cram, "Measurement of Political Effects in the United States Economy: A Study of the 1992 Presidential Election," Economics \& Politics, XXXI (1999), 51-81.

[8] Knight, B.G., "Are Policy Platforms Capitalized into Equity Prices? Evidence from the Bush/Gore 2000 Presidential Election," NBER Working Paper No. W10333 (2004).

[9] Mattozzi, A., "Policy Uncertainty, Electoral Securities and Redistribution," mimeo, 2003.

[10] Musto, D.K. and B. Yilmaz, "Trading and Voting," Journal of Political Economy, CXI (2003), 990-1003. 
[11] Pantzalis, C., D.A. Stangeland, and H. J. Turtle, "Political Elections and the Resolution of Uncertainty: The International Evidence," Journal of Banking and Finance, XXIV (2000), 1575-1603.

[12] Roberts, B.E., "Political Institutions, Policy Expectations, and the 1980 Election: A Financial Market Perspective," American Journal of Political Science, XXXIV (1990), 289-310.

[13] Santa-Clara, P. and R. Valkanov, "The Presidential Puzzle: Political Cycles and the Stock Market," Journal of Finance, LVIII (2003), 1841-1872. 
Table I

\begin{tabular}{|l|c|}
\hline \multicolumn{2}{|c|}{ Bush Portfolio } \\
\hline \hline Corporation & Contibution \\
\hline Philip Morris & $\$ 3,814,051$ \\
MBNA Corp & $\$ 3,565,205$ \\
United Parcel Service & $\$ 2,918,969$ \\
Credit Suisse First Boston & $\$ 2,567,726$ \\
Enron Corp & $\$ 2,501,058$ \\
Pfizer Inc & $\$ 2,472,166$ \\
Bristol-Myers Squibb & $\$ 2,364,412$ \\
Union Pacific Corp & $\$ 1,858,194$ \\
GlaxoSmithKline & $\$ 1,796,893$ \\
WorldCom Inc & $\$ 1,786,370$ \\
\hline
\end{tabular}

Table II

\begin{tabular}{|l|c|}
\hline \multicolumn{2}{|c|}{ Gore Portfolio } \\
\hline \hline Corporation & Contibution \\
\hline Goldman Sachs & $\$ 4,382,527$ \\
Time Warner & $\$ 2,373,005$ \\
Vivendi Universal & $\$ 2,119,810$ \\
Viacom Inc & $\$ 1,552,325$ \\
Loral Space \& Communications & $\$ 1,528,200$ \\
FleetBoston Financial & $\$ 1,377,775$ \\
Vyyo Inc & $\$ 1,359,000$ \\
Bear Stearns & $\$ 1,235,629$ \\
Slim-Fast Foods/Thompson Medical & $\$ 1,194,950$ \\
Cablevision Systems & $\$ 1,026,104$ \\
\hline
\end{tabular}




\section{Table III}

\begin{tabular}{|c|c|c|}
\hline \multicolumn{3}{|c|}{ OLS Regressions } \\
\hline Dependent Variable & RBush-RF & RGore-RF \\
\hline \multirow{4}{*}{$\operatorname{RIPSM}(\mathrm{t}-1)$} & $0.3250^{*}$ & $1.6932 * *$ \\
\hline & $(0.1357)$ & $(0.1792)$ \\
\hline & $0.0526 * *$ & $-0.0704^{*}$ \\
\hline & $(0.0189)$ & $(0.0330)$ \\
\hline No. Obs. & 134 & 134 \\
\hline F-statistics $(2,132)$ & 5.9348 & 44.8876 \\
\hline Jarque-Bera & 0.4232 & 0.5914 \\
\hline Arch LM Test Prob (1 lag) & 0.4833 & 0.0076 \\
\hline ey-West HAC consistent & $\mathrm{s}$ are in $\mathrm{pa}$ & \\
\hline
\end{tabular}

Table IV

\begin{tabular}{|c|c|c|}
\hline \multicolumn{3}{|c|}{ OLS Regressions } \\
\hline Dependent Variable & RBush & RGore \\
\hline \multirow[t]{2}{*}{ Constant } & 0.0311 & -0.0981 \\
\hline & $(0.2409)$ & $(0.2674)$ \\
\hline \multirow[t]{2}{*}{$\mathrm{RM}$} & $0.3250 *$ & $1.6933 * *$ \\
\hline & $(0.1361)$ & $(0.1796)$ \\
\hline \multirow[t]{2}{*}{$\operatorname{RIPSM}(\mathrm{t}-1)$} & $0.0526^{* *}$ & $-0.0701 *$ \\
\hline & $(0.0191)$ & $(0.0331)$ \\
\hline No. Obs. & 134 & 134 \\
\hline $\mathrm{R} 2$ & 0.097 & 0.485 \\
\hline F-statistics & 7.0268 & 61.6169 \\
\hline Jarque-Bera & 0.4221 & 0.5947 \\
\hline Arch LM Test Prob (1 lag) & 0.4804 & 0.0076 \\
\hline $\mathrm{y}$-West HAC consistent & are in $p$ & \\
\hline
\end{tabular}




\section{Table V}

\begin{tabular}{|c|c|}
\hline \multicolumn{2}{|c|}{ GARCH (1,1) } \\
\hline \hline Dependent Variable & RGore-RF \\
\hline RM-RF & $1.7674^{* *}$ \\
& $(0.1645)$ \\
RIPSM(t-1) & $-0.0703^{*}$ \\
& $(0.0325)$ \\
\hline Variance equation & 1.8059 \\
Constant & $(1.7068)$ \\
& 0.0838 \\
ARCH(1) & $(0.0699)$ \\
& $0.7973^{* *}$ \\
GARCH(1) & $(0.1542)$ \\
\hline No. Obs. & 134 \\
R2 & 0.484 \\
\hline Arch LM Test Prob (1 lag) & 0.4539 \\
\hline HAC consistent standard errors are in parentheses
\end{tabular}

\section{Table VI}

\begin{tabular}{|c|c|c|}
\hline \multicolumn{3}{|c|}{ Least Absolute Value } \\
\hline \hline Dependent Variable & RBush & RGore \\
\hline Constant & -0.2646 & -0.3701 \\
& $(0.4311)$ & $(0.4899)$ \\
RM & 0.2909 & $1.7929^{* *}$ \\
& $(0.1918)$ & $(0.2219)$ \\
RIPSM(t-1) & $0.0748^{*}$ & -0.0624 \\
& $(0.0328)$ & $(0.0351)$ \\
\hline No. Obs. & 134 & 134 \\
Pseudo R2 & 0.044 & 0.229 \\
& & 34.21 \\
\hline \multirow{2}{*}{ F-statistics } & 3.78 & \\
\hline
\end{tabular}




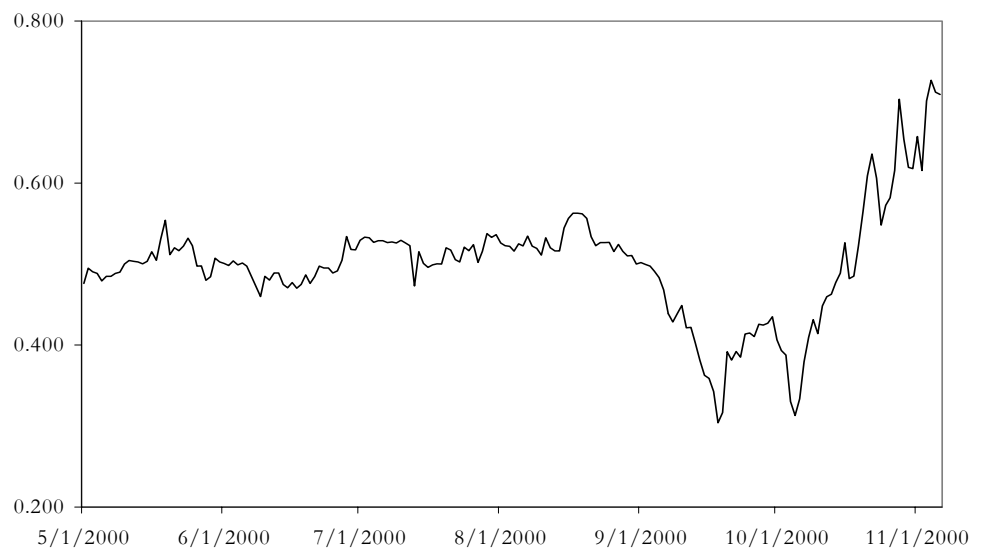

Figure I: IPSM Closing Price of a Bush Contract

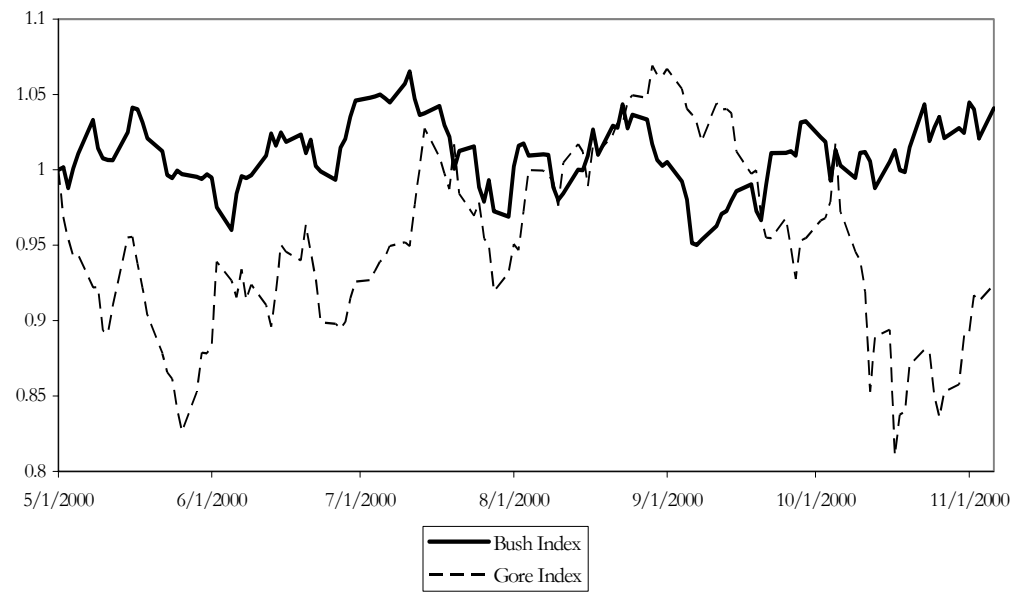

Figure II: Presidential Indexes 


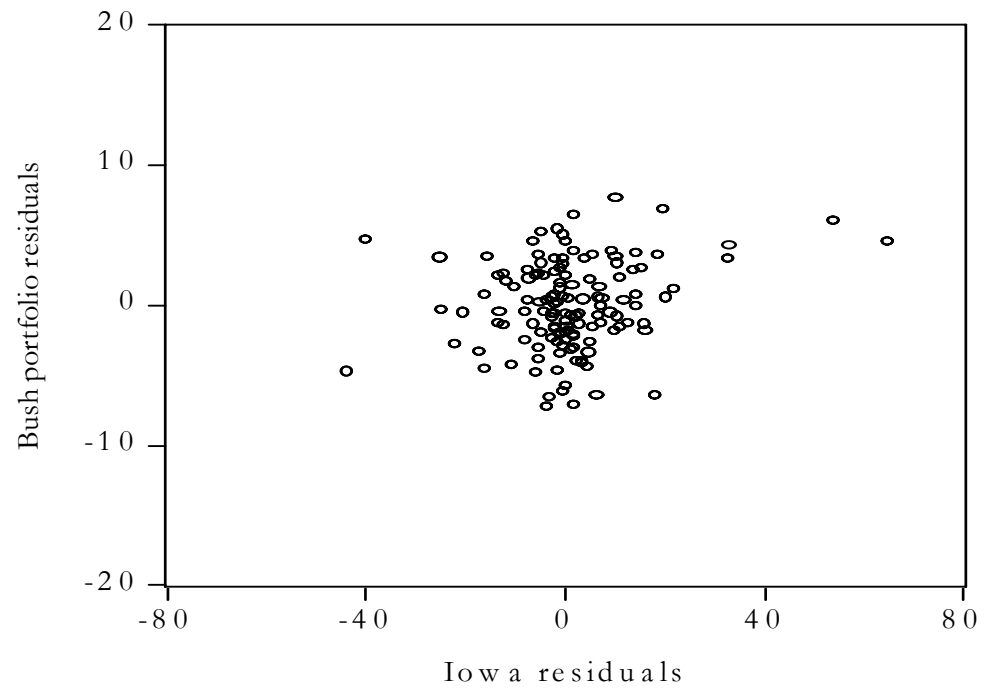

Figure III

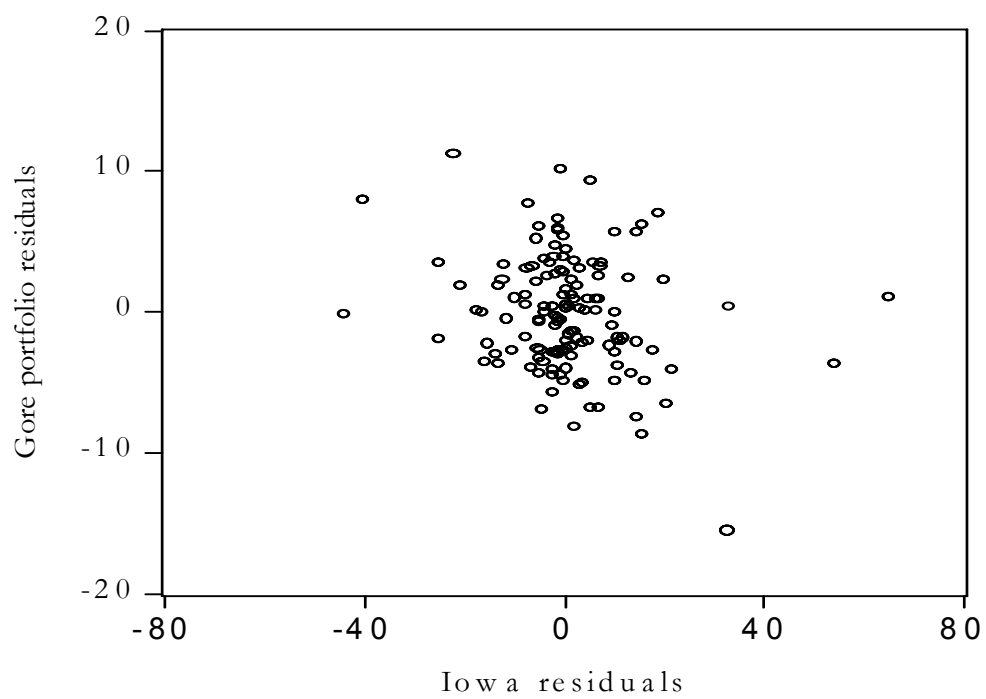

Figure IV 